\title{
Correlation of compound muscle action potential generated by donor nerves with the recovery of elbow flexion in Oberlin transfer in brachial plexus injury
}

\author{
Mukund Ramchandra Thatte, Binita Bharat Raut ${ }^{1}$, Amita Shivyogi Hiremath, \\ Sushil Ramesh Nehete, Nayana Somala Nayak \\ Department of Plastic Surgery, Bombay Hospital and Institute of Medical Sciences, Mumbai, Maharashtra, ${ }^{1}$ Department of \\ Plastic Surgery, KLE University's J. N. Medical College, Belagavi, Karnataka, India
}

Address for correspondence: Dr. Mukund Ramchandra Thatte, Department of Plastic Surgery, Bombay Hospital and Institute of Medical Sciences, Room No 6, $2^{\text {nd }}$ Floor, New Wing, Bombay Hospital, 12, Marine Lines, Mumbai - 400002 , Maharashtra, India.

E-mail: mthatte@gmail.com

\section{ABSTRACT}

Objective: To study the correlation of compound muscle action potential of donor nerves with the recovery of elbow flexion in Oberlin transfer in brachial plexus injury. Introduction: Distal nerve transfer using motor fascicle of ulnar or median nerve to restore elbow flexion is a part of reconstructive surgery after upper brachial plexus injury, first described by Oberlin et al. However, one of the most critical influences on functional outcome is number of functioning motor axons in donor fascicle which is reflected by its compound muscle action potential. We studied whether nerve transfers with donor nerves showing higher amplitudes will yield better reinnervation of muscle and therefore better function as estimated by clinical examination. Methods: We prospectively studied 30 cases of upper brachial plexus injury, of which were treated with Oberlin transfer using ulnar or median or both nerves. The prerequisites were no elbow flexion and hand and wrist flexors showing the power of more than Medical research Council MRC Grade 4. Donor nerves selected either ulnar or median having CMAP $>4 \mathrm{mv}$ in our electrophysiology laboratory during nerve conduction study. Patients were followed up for 1 year and assessed clinically for restoration of elbow flexion, weight tolerance. Results: A total of 30 patients of Oberlin transfer were evaluated for improvement power of biceps and elbow flexion. (MRC) grading was done at 1 year. Twenty-seven patients had a good result (MRC grade $\geq 3$ ), i.e., $90 \%$ of patients. Based on the MRC grades, we categorised the patients into two groups as follows: Group A and Group B. Group A included patients with MRC Grade 4-5 and Group B included Grades 3-3.5. We tried to establish a correlation between CMAP and MRC scores by comparison of MRC grade patients for their pre CMAPs which revealed a statistically significant higher CMAPs between the groups. (MannWhitney U-test, $P=0.028$ ). This indicates the association of higher pre-CMAPs with higher MRC grades. Conclusion: We conclude that

This is an open access journal, and articles are distributed under the terms of the Creative Commons Attribution-NonCommercial-ShareAlike 4.0 License, which allows others to remix, tweak, and build upon the work non-commercially, as long as appropriate credit is given and the new creations are licensed under the identical terms.

\begin{tabular}{|l|l|}
\hline \multicolumn{2}{|c|}{ Access this article online } \\
\hline Quick Response Code: & Website: \\
\hline & www.ijps.org \\
\cline { 2 - 2 } & DOI: \\
\hline
\end{tabular}

For reprints contact: reprints@medknow.com

How to cite this article: Thatte MR, Raut BB, Hiremath AS, Nehete SR, Nayak NS. Correlation of compound muscle action potential generated by donor nerves with the recovery of elbow flexion in Oberlin transfer in brachial plexus injury. Indian J Plast Surg 2018;51:137-44. 
higher the compound muscle action potential of donor nerves, better the recovery of elbow flexion in Oberlin transfer in brachial plexus injury.

\section{KEY WORDS}

CMAP of donor's nerves; elbow flexion; Oberlin transfer

\section{INTRODUCTION}

n brachial plexus injury involving $\mathrm{C}_{5}$ and $\mathrm{C}_{6}$ roots, one of the major objectives in the treatment is the restoration of elbow flexion followed by shoulder stabilisation. Nerve grafting and nerve transfer have played a key role in total brachial plexus reconstruction; however, distal nerve transfers are gaining importance in nerve recovery due to their proximity to target muscle and reliable and robust axon source. Oberlin in 1994 was the first to describe the transfer of part of the ulnar nerve to the nerve to biceps for early restoration of elbow flexion. ${ }^{[1]}$ This is now one of the most widely used procedure to reinnervate biceps in patients who suffered an upper root injury. Mackinnon et al. developed the double fascicular transfer, the addition of a median nerve fascicle transfer to a branch of musculocutaneous nerve supplying the brachialis muscle to improve elbow flexion. ${ }^{[2]}$ The results of these transfers were seen to be generally Medical Research Council (MRC) Grade 4 and no significant morbidity was noted in donor innervated muscles. ${ }^{[2,3]}$ Post-operative elbow flexion after nerve transfer depends on several factors like patient age ${ }^{[4-6]}$ time from injury to surgery, ${ }^{[3,4,7-9]}$ etc., but the most critical being the number of good quality functioning motor neurons in the donor fascicle..$^{[10,11]}$ This depends on the condition of the donor nerves, which can be determined by the electrodiagnostic study ${ }^{[2]}$ and is represented by the compound muscle action potential (CAMP). ${ }^{[13]}$ In our paper, we study whether the functional outcome is superior when nerves with higher CMAP amplitudes, recorded on pre-operative electromyography (EMG) are used as donors. No previous studies reveal a co-relation with pre-operative CMAP of donor nerve and outcome.

\section{METHODS}

The Institutional Review Board approval was obtained for this study, and informed consent was taken from each patient before recruitment. This is a prospective study of 30 adult patients of brachial plexus injury having upper trunk $\mathrm{C}_{5} \mathrm{C}_{6}$ palsy who presented in our department from January 2011 to December 2012 and fulfilled the following eligibility criteria.

\section{Eligibility criteria}

1. Upper brachial plexus injury with no elbow flexion and good elbow extension (except one patient)

2. Nerve conduction study showing CMAP of more than $4 \mathrm{mv}$ (our electrophysiology Laboratory standard) in distal ulnar and/or median nerve innervated muscles such as abductor digiti minimi (ADM)/flexor carpi ulnaris (FCU) and abductor pollicus brevis (APB)/flexor carpi radialis (FCR)

3. Hand and wrist flexors showing power more than MRC Grade 4.

\section{MRC grading of power}

- 0 -No contraction

- 1 Flicker or trace of contraction

- 2 Active movement, with gravity eliminated

- 3 Active movement against gravity

- 4 Active movement against gravity and resistance

- 5 Normal power.

\section{Exclusion criteria}

Patients with global brachial plexus injury and with $\mathrm{C}_{7}$ root involvement were not included in the study.

An electrodiagnostic study (EDx) was performed for diagnostic purpose and to document the CMAP of median and ulnar nerve innervated muscles, namely, (ADM)/(FCU) and $(\mathrm{APB}) /(\mathrm{FCR})$. The potential donor nerve with higher CMAP amplitude was selected as a donor for the motor fascicle. Patients in which double nerve transfer was done, average of CMAP's of both the donor's nerves was taken. Patients underwent either Oberlin or Mackinnon type of transfer, in addition typically spinal accessory nerve (XI) to suprascapular nerve (SSN) and other appropriate nerve coaptations were done, but they are not germane to this study.

We recorded patient details according to a pro forma which included age, sex, sidedness of injury, the delay between injury and surgery and details of surgery, i.e which nerve transfer was performed. Follow-up examinations were carried out every 3 months and the MRC grade of elbow flexion was noted. However, only 
MRC grade at the end of 1 year was considered for analysis. MRC grade of $2+, 3+, 4+$ is taken as $2.5,3.5$, 4.5 for statistical analysis. MRC grade of elbow flexion at 1 year follow-up was recorded, and patients were divided in two groups. Based on the MRC grades, we categorised the patients into two groups, Group A and Group B. Group A included patients with MRC Grade 4-5 and Group B included Grades 3-3.5. The outcome was evaluated by improvement of MRC grade of elbow flexion pre- and post-nerve transfer surgery. Regression analysis was attempted to evaluate the predictors of higher MRC grades (excellent $=5$, good $=4$ and 4.5 , adequate $=3$ and 3.5). The model included age, duration of injury, CMAPs of median $\left(\mathrm{CMAP}_{\text {median }}\right)$, ulnar $\left(\mathrm{CMAP}_{\text {ulnar }}\right)$ nerves, type of anastomosis (whether it includes median or ulnar, yes versus no) and higher CMAPs (maximum, CMAP ${ }_{\max }$ ).

Three patients were not included because two patients were lost on follow-up and one had delayed surgery thus considering 27 patients for final analysis.

\section{Operative technique}

All patients underwent a normal supra clavicular exploration by an approach described by Thatte M R to determine the nature and extent of the injury and to perform the $\mathrm{XI}^{\text {th }}$ Nerve to SSN transfer. ${ }^{[14]}$ Subsequently, an Oberlin type distal transfer was performed as described below.

A longitudinal incision measuring $10-12 \mathrm{~cm}$ is taken on the upper and medial aspect of the arm between the biceps-triceps space [Figure 1]. The ulnar nerve lies medial and posterior to the median nerve and is identified behind the medial inter-muscular septum in the upper $3^{\text {rd }}$ of the arm [Figure 2]. Musculocutaneous nerve was identified in the groove between biceps and brachialis muscle and traced proximally to coracobrachialis and distally until it continues as lateral antebrachial cutaneous nerve [Figure 3]. The branch supplying biceps and brachialis were identified, by retracting biceps muscle; biceps branch being typically given out proximally than branch to brachialis [Figure 4]. Once all the nerves were identified and isolated with vascular loops, the donor nerve was selected on the basis of CMAP, measured on EDx done preoperatively, and was stimulated intra-operative with nerve stimulator with a current of low intensity to confirm a motor fascicle supplying FCU/FCR if it could be identified. This is not always possible, but Bhandari and Deb have shown that this need not be mandatory. ${ }^{[15]}$ Dissection was done under high power

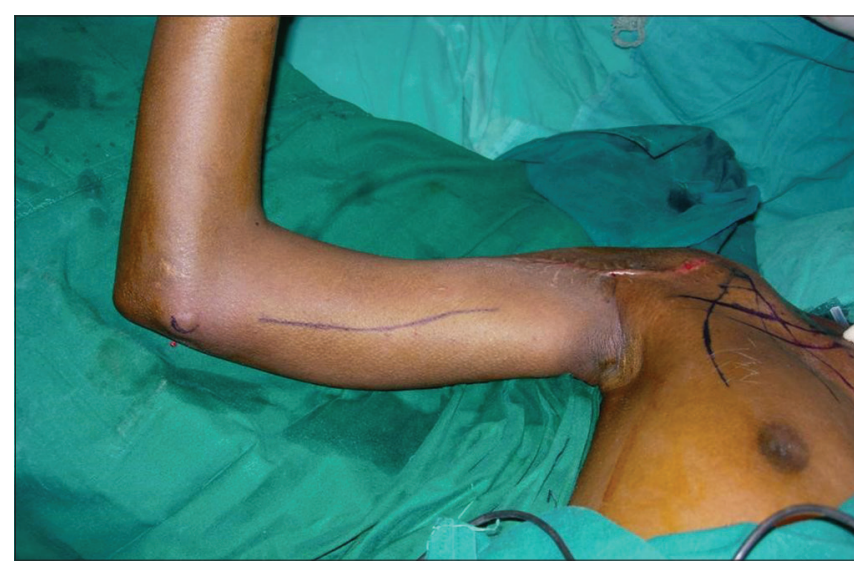

Figure 1: Incision for Oberlin surgery

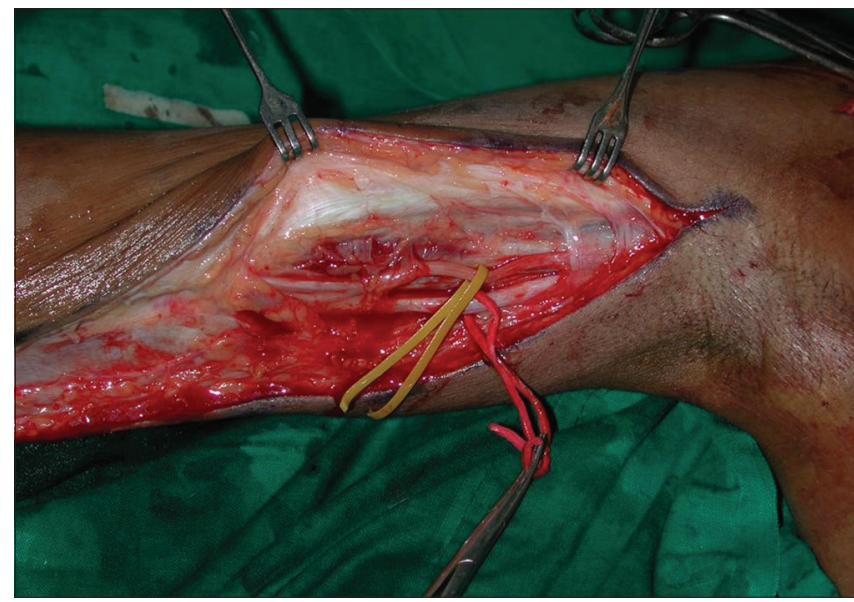

Figure 2: Median and ulnar nerves

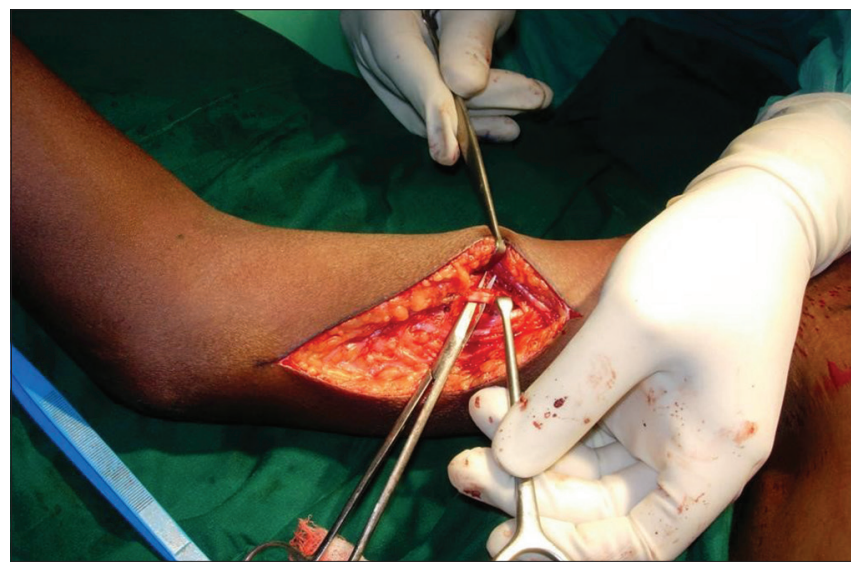

Figure 3: Musculocutaneous nerve and median nerve

magnification, epineurotomy of either median, ulnar or both nerves was done and one or two fascicles were taken as donor depending on the size of the recipient nerve, i.e., branch to biceps and branch to brachialis (if the double transfer was done). Contractions of respective muscles were seen as confirmation of correct fascicle selection, i.e., wrist flexors. The musculocutaneous nerve branches Indian Journal of Plastic Surgery Volume 51 Issue 2 May-August 2018 
to the biceps and brachialis muscles were dissected and cut to get a good length for tension free transfer. The selected donor fascicle was co-apted end-to-end to the biceps and in case of double transfer additionally to the brachialis branch with a single $9-0$ or $10-0$ nylon suture supplemented with fibrin glue [Figures 5 and 6]. The co-aptation was always done without any tension.

Hand strength was also checked to document any deterioration in activity of extrinsic and intrinsic muscles postoperatively. All patients had a strong hand function preoperatively as mentioned in the inclusion criteria

All data were analysed using the Mann-Whitney U test, with $P<0.05$ taken as statistically significant. Regression analysis of MRC grade was done, with possible predictors. $95 \%$ confidence intervals with $P$ (adjusted $\mathrm{P})<0.05$ was considered as statistically significant.

\section{RESULTS}

After inclusion criteria, we observed following as demographic and other variables recorded. We had 27 patients, total, with mean standard deviation (SD) age of 32.3 (13.1) years, the maximum age of 62 years [Table 1]. We had only 1 female patient among them and 5 left brachial plexus injury. Three patients did not meet the inclusion criteria either because of loss of follow-up or delayed surgery thus considering 27 patients for final analysis.

All the patients were operated after 2 months from injury and the mean (SD) period from injury to surgery was 4.56 (5.47) months. The mean (SD) of ulnar, median CMAPs recorded were 12.48 (4.85) and 12.09 (3.88), respectively. The mean $(\mathrm{SD})$ of maximum CMAP recorded was 13.44 (4.23) for either [Table 1].

In the end, we had 14 ulnar nerve fascicles, 5 median nerve fascicles and 11 both nerve fascicles for coaptation

\begin{tabular}{|c|c|c|c|c|c|c|c|c|}
\hline Variable & $n$ & Mean & SEM & $S D$ & Min & Median & Max & Range \\
\hline Age & 27 & 32.3 & 2.5 & 13.1 & 16.0 & 27.0 & 62.0 & 46.0 \\
\hline Days of Injury & 27 & 116.3 & 14.7 & 76.4 & 34.0 & 86.0 & 276.0 & 242.0 \\
\hline $\mathrm{CMAP}_{\text {Unnar }}$ & 27 & 12.5 & 0.9 & 4.8 & 4.9 & 11.6 & 23.7 & 18.8 \\
\hline $\mathrm{CMAP}_{\text {Median }}$ & 27 & 12.1 & 0.7 & 3.9 & 5.2 & 11.6 & 23.2 & 18.0 \\
\hline $\mathrm{CMAP}_{\text {Max }}$ & 27 & 13.4 & 0.8 & 4.2 & 6.4 & 13.3 & 23.7 & 17.3 \\
\hline
\end{tabular}

SD: Standard deviation, SEM: Standard mean of error, CMAP: Compound Muscle Action Potential

Indian Journal of Plastic Surgery Volume 51 Issue 2 May-August 2018 to nerve to biceps or nerve to brachialis were used in the study.

The results, i.e MRC grade of elbow flexion at 1 year follow-up was recorded and patients were divided into

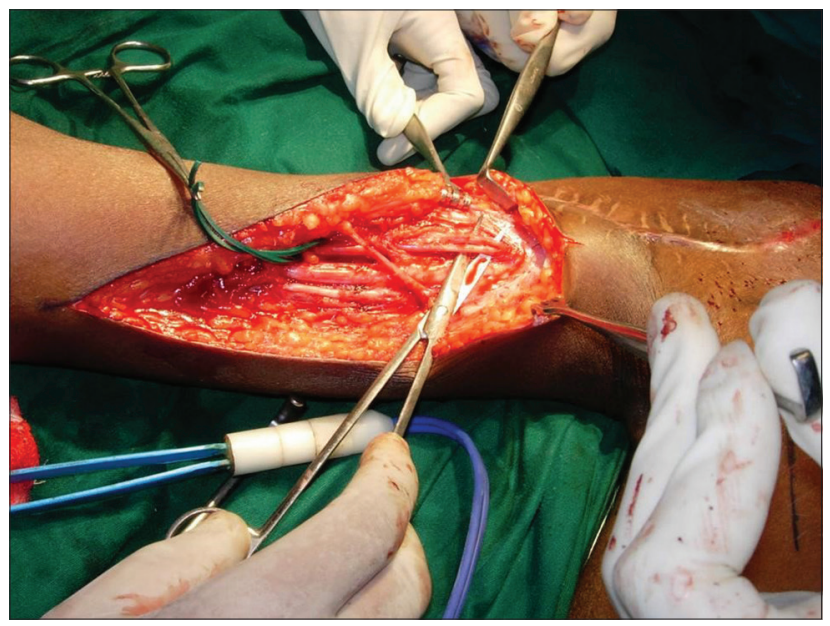

Figure 4: Branch to biceps

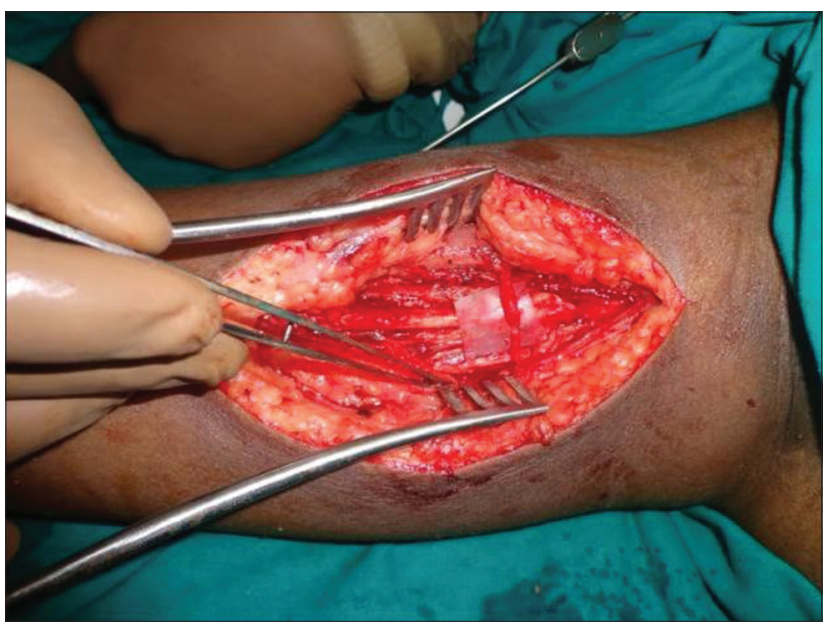

Figure 5: Ulnar nerve fascicle transferred to branch to biceps

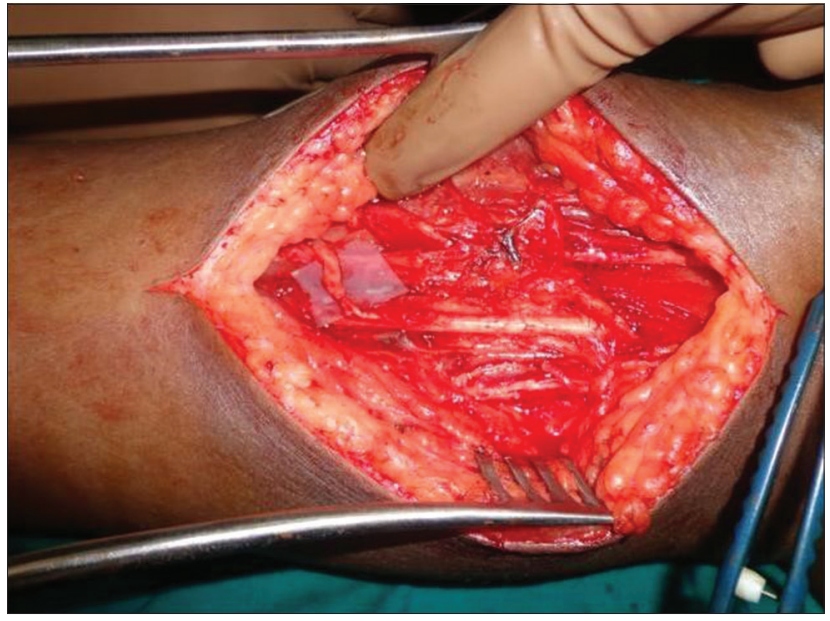

Figure 6: Median nerve fascicle transferred to branch to brachialis 
two groups. The outcome was evaluated by improvement of MRC grade of elbow flexion pre- and post-nerve transfer surgery and correlated to see if improvement is significantly better in cases where donor nerve of higher CMAP amplitude was used.

We observed 11 patients had Grade 4 or higher MRC and 16 patients in MRC Grade of 3 or 3.5. There was a single case in which MRC Grade 5 recovery of elbow flexors were seen [Figure 7 and 8]. Based on the MRC grades, we categorised the patients into two groups, Group A and Group B [Table 2]. The comprehensive data of grouped patients are described in Table 3.

Comparison of MRC grade subjects for their pre-CMAPs revealed a statistically significant higher CMAPs between the groups (Mann-Whitney U-test, $P=0.028$ ). This indicates the association of higher pre-CMAPs with higher MRC grades.

Ordinal logistic regression analysis was attempted to evaluate the predictors of higher MRC grades (excellent $=5$, good $=4$ and 4.5 , adequate $=3$ and 3.5) using the regression model, the model included age, duration of injury, CMAPs of median, ulnar nerves, type of anastomosis (level) and higher CMAPs (max). The model fit was checked using log likely hood values $(-11.2, P=0.011)$, Pearsons $P,(P=0.343)$, deviance

Table 2: Groups according to medical research council grades

\begin{tabular}{lll}
\hline Groups & MRC grade & $\boldsymbol{n}$ \\
\hline Group A & MRC grade 4-5 & 11 \\
Group B & MRC grade 3, 3.5 & 16 \\
Total & & 27 \\
\hline
\end{tabular}

MRC: Medical research council

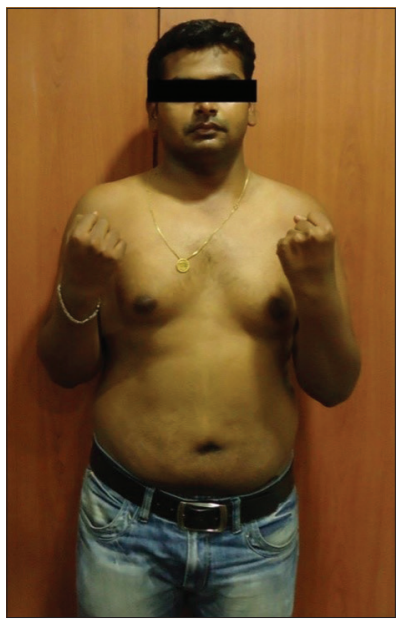

Figure 7: Post-operative result of Oberlin transfer
$P(P=654)$. However, no single predictor was identified which significantly affected the MRC grades in the presence of covariables. This means that in the presence of other covariables, the higher CMAP effect will not affect the MRC [Table 4].

\section{Distal hand function}

In our series, two patients developed paraesthesia along the little finger which was self-limiting and subsided in 4 months. No deficit was seen in motor function, grip strength was the same or better in all patients pre- and post-operatively.

\section{DISCUSSION}

Oberlin transfer is a standard procedure for restoration of elbow flexion in patients of upper brachial plexus injury C5C6. Majority of the patients had the satisfactory outcome of MRC grade $\geq 3$. (i.e. 27 of our 30 patients had satisfactory result i.e. $90 \%$ of patients). Eleven patients showed excellent results of MRC Grade 4, 4.5 and 5. One patient in our series had elbow flexion of MRC Grade 5 and could lift $5 \mathrm{~kg}$ weight.

In Oberlin series, 4 patients underwent nerve transfer out of which MRC Grade 4 elbow flexion was seen in two patients while other 2 had MRC Grade 3 elbow flexion. ${ }^{[1]}$ Similarly, in O. Suzuki series, 8 patients underwent Oberlin transfer, leaving the first two patients rest all had MRC Grade 4 elbow flexion. ${ }^{[16]}$ Poor result of MRC Grade 2 was seen in previous 2 patients. In Teboul's series, out of 32 patients, 20 patients had a good result with MRC $>4,4$ patients had the fair result, MRC 3 and 8 had poor result MRC $<2$.

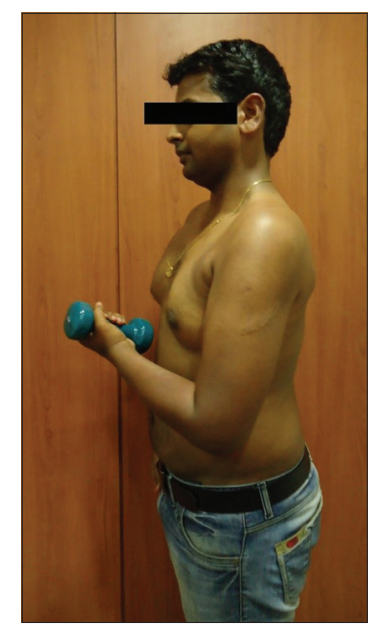

Figure 8: Elbow flexion of MRC Grade 4+

Indian Journal of Plastic Surgery Volume 51 Issue 2 May-August 2018 
Table 3: Medical research council groups distribution

\begin{tabular}{|c|c|c|c|c|c|c|}
\hline Age & Sex & Diagnosis & Ulnar nerve CMAP & Median nerve CMAP & Details of surgery & MRC grade elbow flexion \\
\hline \multicolumn{7}{|c|}{ Group A } \\
\hline 21 & Male & Lt BPI & 10.1 & 12.3 & Un $\rightarrow$ bis, $\mathrm{mn} \rightarrow$ brc, san $\rightarrow$ ssn & 4 \\
\hline 25 & Male & Rt BPI & 15 & 12.6 & Un $\rightarrow \mathrm{mcn}$, san $\rightarrow \mathrm{ssn}$ & 4 \\
\hline 19 & Male & Rt BPI & 14.5 & 14.8 & $\mathrm{Un} \rightarrow \mathrm{mcn}, \mathrm{mn} \rightarrow \mathrm{mcn}, \mathrm{san} \rightarrow \mathrm{ssn}$ & 4.5 \\
\hline 27 & Male & Lt BPI & 14.3 & 11.6 & $\mathrm{Un} \rightarrow \mathrm{mcn}, \operatorname{trp} \rightarrow \mathrm{axl}, \mathrm{san} \rightarrow \mathrm{ssn}$ & 5 \\
\hline 49 & Male & Lt BPI & 23.7 & 16.6 & Un $\rightarrow$ bis, san $\rightarrow$ ssn, $\operatorname{trp} \rightarrow$ axl & 4.5 \\
\hline 33 & Male & Rt BPI & 16.7 & 13.5 & $\mathrm{Un} \rightarrow \mathrm{mcn}, \operatorname{trp} \rightarrow \mathrm{axl}, \mathrm{san} \rightarrow \mathrm{ssn}$ & 4 \\
\hline 35 & Male & Rt BPI & 12.1 & 9.3 & Un $\rightarrow$ bis, san $\rightarrow$ ssn & 4.5 \\
\hline 23 & Male & Lt BPI & 17.6 & 17 & Un $\rightarrow$ mcn, $\operatorname{trp} \rightarrow$ axl, san $\rightarrow$ ssn & 4 \\
\hline 16 & Female & Rt BPI & 10.1 & 10.8 & $\mathrm{Mn} \rightarrow$ bis, un $\rightarrow$ brc & 4.5 \\
\hline 18 & Male & Rt BPI & 14.8 & 23.2 & $\mathrm{Mn} \rightarrow \mathrm{mcn}, \operatorname{trp} \rightarrow \mathrm{axl}$ & 4.5 \\
\hline 19 & Male & Rt BPI & 8.7 & 16.9 & Un $\rightarrow$ bis, mn $\rightarrow$ brc, san $\rightarrow$ ssn, 3,4 icn $\rightarrow \operatorname{trp}$ & 4 \\
\hline \multicolumn{7}{|c|}{ Group B } \\
\hline 48 & Male & Lt BPI & 6.4 & 5.2 & Un $\rightarrow$ bis, $\mathrm{mn} \rightarrow$ brc, $\operatorname{trp} \rightarrow$ axl, san $\rightarrow$ ssn & 3 \\
\hline 51 & Male & Rt BPI & 9.5 & 8.5 & $\mathrm{Un} \rightarrow$ brc, $\mathrm{mn} \rightarrow$ bis, san $\rightarrow$ ssn, trp $\rightarrow$ axl & 3.5 \\
\hline 38 & Male & Rt BPI & 5.4 & 7.3 & $\mathrm{Un} \rightarrow \mathrm{mcn}, \mathrm{mn} \rightarrow \mathrm{mcn}, 3,4 \mathrm{icn} \rightarrow \operatorname{trp}, \mathrm{san} \rightarrow \mathrm{pc}$ & 3.5 \\
\hline 20 & Male & Rt BPI & 9.6 & 8.9 & San $\rightarrow$ ssn, un $\rightarrow$ mcn, trp $\rightarrow$ axl & 3 \\
\hline 25 & Male & Rt BPI & 11.6 & 10.9 & $\mathrm{Un} \rightarrow \mathrm{mcn}, \operatorname{trp} \rightarrow \mathrm{axl}$ & 3 \\
\hline 56 & Male & Rt BPI & 5.6 & 8.2 & $\mathrm{Mn} \rightarrow \mathrm{mcn}, \operatorname{trp} \rightarrow \mathrm{axl}, \mathrm{san} \rightarrow \mathrm{ssn}$ & 3.5 \\
\hline 28 & Male & Rt BPI & 16.6 & 14.3 & Un $\rightarrow$ bis, $\mathrm{mn} \rightarrow$ bis & 3 \\
\hline 30 & Male & Rt BPI & 17.1 & 13.8 & $\mathrm{Un} \rightarrow \mathrm{mcn}, \operatorname{trp} \rightarrow \mathrm{axl}$ & 3.5 \\
\hline 27 & Male & Rt BPI & 11.6 & 9.6 & $\mathrm{Un} \rightarrow \mathrm{mcn}, \mathrm{san} \rightarrow \mathrm{ssn}$ & 3 \\
\hline 52 & Male & Rt BPI & 6.9 & 9.9 & $\mathrm{Mn} \rightarrow \mathrm{mcn}, \mathrm{san} \rightarrow \mathrm{ssn}$ & 3.5 \\
\hline 24 & Male & Rt BPI & 13.5 & 13.2 & $\mathrm{Un} \rightarrow \mathrm{mcn}, \mathrm{san} \rightarrow \mathrm{ssn}$ & 3.5 \\
\hline 25 & Male & Rt BPI & 9.6 & 13.3 & Mn-brc, un-bis, san-ssn & 3 \\
\hline 30 & Male & Rt BPI & 16.3 & 16.8 & $\mathrm{Mn} \rightarrow$ bis, san $\rightarrow$ ssn & 3 \\
\hline 45 & Male & Rt BPI & 22.4 & 10.5 & Un $\rightarrow$ bis, $\mathrm{mn} \rightarrow$ brc, san $\rightarrow$ ssn, trp $\rightarrow$ axl & 3 \\
\hline 62 & Male & Rt BPI & 11.2 & 8.8 & Un $\rightarrow$ bis, san $\rightarrow$ ssn & 3 \\
\hline 26 & Male & Rt BPI & 4.9 & 9.6 & $\mathrm{Mn} \rightarrow \mathrm{mcn}, \operatorname{trp} \rightarrow \mathrm{axl}$ & 3.5 \\
\hline
\end{tabular}

Un: Ulnar Nerve, Mn: Median Nerve, Bis: Nerve to Biceps, Brc: Nerve to Brachialis, Mcn: Musculocutaneous nerve, San: Spinal Accessory Nerve, Ssn: Suprascapular Nerve, Trp: Nerve to Nerve to Triceps, Axl: Axillary Nerve, icn: Intercostal nerve, Pc: Posterior cord, CMAP: Compound Muscle Action Potential, Rt BPI: Right brachial plexus injury, Lt BPI: Left brachial plexus injury, MRC: Medical research council

Table 4: Regression analysis of medical research council grade with possible predictors

\begin{tabular}{lcccccc}
\hline Predictor & Coef & SE Coef & $\boldsymbol{P}$ & OR & \multicolumn{2}{c}{$\mathbf{9 5 \%} \mathbf{C l}$} \\
\hline Age & -0.005 & 0.037 & 0.901 & 1 & 0.93 & 1.07 \\
Days of Injury & 0.003 & 0.006 & 0.61 & 1 & 0.99 & 1.02 \\
CMAP $_{\text {Ulnar }}$ & -0.029 & 0.212 & 0.892 & 0.97 & 0.64 & 1.47 \\
CMAP $_{\text {Median }}$ & 0.276 & 0.242 & 0.254 & 1.32 & 0.82 & 2.12 \\
CMAP $_{\text {Max }}$ & -0.070 & 0.312 & 0.823 & 0.93 & 0.51 & 1.72 \\
Ulnar (yes versus no) & 0.663 & 1.338 & 0.62 & 1.94 & 0.14 & 26.71 \\
Median (yes versus no) & 0.777 & 0.935 & 0.406 & 2.17 & 0.35 & 13.59 \\
\hline
\end{tabular}

SE: Standard error, OR: Odds ratio, Cl: Confidence interval, CMAP: Compound Muscle Action Potential. 95\% confidence intervals with $P$ adjusted $P<0.05$ was considered as statistically significant

11 patients underwent Steindler flexorplasty to increase elbow flexion strength. ${ }^{[17]}$ Leechavengvongs' series showed that 30 of their 32 patients had good results of MRC 3 elbow flexion in average 6 months from the surgery. ${ }^{[18]}$

Thus, literature shows that Oberlin transfer has good MRC grade in most of the series. This is because the co-aptation is done distally, away from the zone of trauma. The donor nerve in this region is healthy and has good number of healthy axons which can be used for co-aptation. Furthermore, the motor end plate of the target muscle, either biceps or brachialis is in close proximity to the donor nerves, i.e. the ulnar and median nerves. No nerve grafts are used. Hence, the time taken for reinnervation is reduced considerably and good results are obtained.

Besides factors such as the age of the patient, the interval between injury and surgery, co-morbidities, the most important factor determining the outcome of surgery is the donor nerve selection. Many researchers have stated about fascicular selection of the donor nerve by the topographical arrangement of the motor fascicle used for co-aptation and that the fascicle situated in the anteromedial part of the nerve supplies the wrist flexor and so that fascicle should be harvested. Subsequently, many researchers have stated various arrangement of the fascicle but no general consensus has been 
obtained. Bhandari, however, concluded that fascicular identification by nerve stimulator is not necessary when executing double nerve transfers. ${ }^{[15]}$ They believe that the fascicular nerve anatomy is so inherently complex that spending extra time using a nerve stimulator attempting to tease out one specific motor fascicle is challenging and is not associated with improved results..$^{[15]}$

O. Suzuki used the technique of intra-operative EMG to select donor nerve fascicle for co-aptation. ${ }^{[16]}$ In his series of 8 patients, he used type A fascicles (mostly motor fibres) and type $B$ fascicles (motor and sensory mixed) among the three evoked potential patterns, for co-aptation in 6 patients. He observed that strong elbow flexion was obtained in patients when type A fascicles were used and recorded a $4 \mathrm{MRC}$ grade in mean 7 months from the time of surgery. He concluded that intra-operative EMG is a good guide for the selection of donor nerve fascicle, avoids selection of damaged fascicles and decreases the donor side morbidity. Many researchers have stated use of intrafascicular dissection and finding out the fascicle which supplies the FCU with a nerve stimulator, but it has been observed that when intra-operative stimulation of each fascicle is done using low intensity of $2 \mathrm{~mA}$ of current, mass movement is produced which makes identification of the fascicle supplying the wrist flexors difficult. ${ }^{[15]}$

In our study, we have used compound muscle action potential of the donor nerves determined by EMG done pre-operatively as factor for selection of donor nerves. CMAP indicates the number of active functioning axons in the donor nerve. ${ }^{[16]}$ Compound muscle action potential (CMAP) is the algebraic sum of many muscle fibre action potentials. ${ }^{[13]}$ The CMAP of all nerves used as donors were recorded and in case of double nerve transfers, an average of the CMAP's of both the nerves was taken. When MRC grade of recipient muscle was compared, it was seen that those receiving donor nerves with higher CMAP values had higher MRC grade. Patients were divided into two groups according to the MRC grade. Group A included patients who had MRC grade of 4, 4.5 and Group B 3, 3.5. Comparison of MRC grade subjects for their pre CMAPs revealed a statistically significant higher CMAPs between the groups (Mann-Whitney $U$ test, $P=0.028$ ). This indicates the association of higher pre CMAPs with higher MRC grades. Ordinal logistic regression analysis was attempted to evaluate the predictors of higher MRC grades (excellent $=5, \operatorname{good}=4$ and 4.5 , adequate $=3$ and 3.5 ) using regression model, however, no single predictor was identified which significantly affected the MRC grades in the presence of covariables. Hence, the presence of other covariables, the higher the CMAP effect will not affect the MRC.

\section{CONCLUSION}

We would like to recommend choosing donor nerves based on CMAP for a better outcome. No study so far has been done showing compound muscle action potential of the nerve (determined by pre-operative electrodiagnostic studies) used as guide for the selection of donor nerve in nerve transfer surgery like Oberlin surgery. Hence in our study, we prove that higher the CMAP of the donor nerve higher will be the MRC grade of elbow flexion. Schreiber et al. also state that preoperative donor nerve EMG is a predictor of nerve transfer outcomes.

Donor site morbidity was another significant issue which needed to be considered while doing a nerve transfer from a healthy functioning nerve. In Oberlin series, it was seen that among the 4 patients, 3 patients did not show significant donor site morbidity. The $4^{\text {th }}$ patient had 2 point discrimination of $10 \mathrm{~mm}$, pinch strength $=4 \mathrm{~kg}$ and grip strength $=12 \mathrm{~kg}$ show some impairment in hand function. ${ }^{[1]}$

In O. Suzuki series, the post-operative grip strength improved over the pre-operative levels in six cases from a mean of $2.4 \mathrm{~kg}(0.6-4.4)$ preoperatively to $3.2 \mathrm{~kg}$ (0.6-6.5) postoperatively. This increase in grasping power and pinch strength was explained on the fact that as the elbow function returns, the hand is better utilised in daily activities and hence increases the overall power of the intrinsic muscles. ${ }^{[16]}$ Schreiber et al. showed no donor site morbidity in their series of 21 Oberlin transfer. $^{[19]}$

Similar observations were seen in all studies that sensory symptoms subsided spontaneously and in our series, no appreciable deficit in ulnar or median nerve function was noted in any of the patients in the follow-up period of 1 year. Donor site morbidity is not significant.

\section{Limitation of the study}

One patient in Group B has nil elbow extension, which defers from our inclusion criteria however it does not detract from the central hypothesis being tested. 


\section{Acknowledgement}

The authors would like to special thanks to Dr. Parag Lad and Dr. Bipin Gangurde for Data collection.

\section{Financial support and sponsorship}

Nil.

\section{Conflicts of interest}

There are no conflicts of interest.

\section{REFERENCES}

1. Oberlin C, Béal D, Leechavengvongs S, Salon A, Dauge MC, Sarcy JJ, et al. Nerve transfer to biceps muscle using a part of ulnar nerve for C5-C6 avulsion of the brachial plexus: Anatomical study and report of four cases. J Hand Surg Am 1994;19:232-7.

2. Mackinnon SE, Novak CB, Myckatyn TM, Tung TH. Results of reinnervation of the biceps and brachialis muscles with a double fascicular transfer for elbow flexion. J Hand Surg Am 2005;30:978-85.

3. Liverneaux PA, Diaz LC, Beaulieu JY, Durand S, Oberlin C. Preliminary results of double nerve transfer to restore elbow flexion in upper type brachial plexus palsies. Plast Reconstr Surg 2006;117:915-9.

4. Lee JY, Kircher MF, Spinner RJ, Bishop AT, Shin AY. Factors affecting outcome of triceps motor branch transfer for isolated axillary nerve injury. J Hand Surg Am 2012;37:2350-6.

5. Verdú E, Ceballos D, Vilches JJ, Navarro X. Influence of aging on peripheral nerve function and regeneration. J Peripher Nerv Syst 2000;5:191-208.

6. El-Gammal TA, El-Sayed A, Kotb MM. Surgical treatment of brachial plexus traction injuries in children, excluding obstetric palsy. Microsurgery 2003;23:14-7.

7. Sedain G, Sharma MS, Sharma BS, MahapatraAK. Outcome after delayed oberlin transfer in brachial plexus injury. Neurosurgery 2011;69:822-7.
8. Ricardo M. Surgical treatment of brachial plexus injuries in adults. Int Orthop 2005;29:351-4.

9. Bentolila V, Nizard R, Bizot P, Sedel L. Complete traumatic brachial plexus palsy. Treatment and outcome after repair. J Bone Joint Surg Am 1999;81:20-8.

10. Wood MB, Murray PM. Heterotopic nerve transfers: Recent trends with expanding indication. J Hand Surg Am 2007;32:397-408.

11. Kakinoki R, Ikeguchi R, Dunkan SF, Nakayama K, Matsumoto T, Ohta S, et al. Comparison between partial ulnar and intercostal nerve transfers for reconstructing elbow flexion in patients with upper brachial plexus injuries. J Brachial Plex Peripher Nerve Inj 2010;5:4.

12. O'Shea K, Feinberg JH, Wolfe SW. Imaging and electrodiagnostic work-up of acute adult brachial plexus injuries. J Hand Surg Eur Vol 2011;36:747-59.

13. Wilbourn AJ. Nerve conduction studies. Types, components, abnormalities, and value in localization. Neurol Clin 2002;20:305-38, v.

14. Thatte MR, Agashe M, Rathod C, Lad P, Mehta R. An approach to the supraclavicular and infraclavicular aspects of the brachia plexus. Tech Hand Up Extrem Surg 2011;15:188-97.

15. Bhandari PS, Deb P. Fascicular selection for nerve transfers: The role of the nerve stimulator when restoring elbow flexion in brachial plexus injuries. J Hand Surg Am 2011;36:2002-9.

16. Suzuki $O$, Sungawa $T$, Yokota $K$. Use of quantitive intra-operative electrodiagnosis during partial ulnar nerve transfer to restore elbow flexion. J Bone Joint Surg Br 2011;93-B; 364.

17. Teboul F, Kakkar R, Ameur N, Beaulieu JY, Oberlin C. Transfer of fascicles from the ulnar nerve to the nerve to the biceps in the treatment of upper brachial plexus palsy. J Bone Joint Surg Am 2004;86-A: 1485-90.

18. Leechavengvongs $\mathrm{S}$, Witoonchart $\mathrm{K}$, Uerpairojkit C, Thuvasethakul P, Ketmalasiri W. Nerve transfer to biceps muscle using a part of the ulnar nerve in brachial plexus injury (upper arm type): A report of 32 cases. J Hand Surg Am 1998;23:711-6.

19. Schreiber JJ, Feinberg JH, Byun DJ, Lee SK, Wolfe SW. Preoperative donor nerve electromyography as a predictor of nerve transfer outcomes. J Hand Surg Am 2014;39:42-9. 